\title{
Applications of electronic noses in meat analysis
}

\author{
Elżbieta GÓRSKA-HORCZYCZAK ${ }^{1 *}$, Dominika GUZEK ${ }^{1}$, Zuzanna MOLĘDA ${ }^{1}$, \\ Iwona WOJTASIK-KALINOWSKA ${ }^{1}$, Marta BRODOWSKA ${ }^{1}$, Agnieszka WIERZBICKA ${ }^{1}$
}

\begin{abstract}
Electronic noses are devices able to characterize and differentiate the aroma profiles of various food, especially meat and meat products. During recent years e-noses have been widely used in food analysis and proved to provide a fast, simple, non-expensive and non-destructive method of food assessment and quality control. The aim of this study is to summarize the most important features of this analytic tool and to present basic fields and typical areas of e-nose use as well as most commonly used sensor types and patterns for e-nose design. Prospects for the future development of this technique are presented. Methods and research results presented in this manuscript may be a guideline for practical e-nose use.
\end{abstract}

Keywords: electronic nose; sensors; gas chromatography; odour.

Practical Application: Review of electronic nose devices usage for measurement of various meat properties.

\section{Introduction}

The most important factors affecting freshness and quality of poultry and fish are colour, texture and flavour. Meat flavour quality is determined by composition of VOC as its critical factor (Acevedo et al., 2012). They should be qualified by electronic nose (e-nose) in the same way as human senses, because these modalities are the basis for human perception of freshness and quality (O'Sullivan \& Kerry, 2009). The odour of meat is formed by a complex mixture of different volatile organic compounds, originating from various reactions. It is often stated that fresh meat is almost unscented and the only odour that can be detected by the consumer is described as "bloody" (Khan et al., 2015). During storage or thermal processes, the precursors of the aroma constituents undergo oxidation and decomposition reactions leading to a number of products which can then react further providing organic compounds of low molecular mass and usually these secondary products are responsible for odour development (O’Sullivan \& Kerry, 2009).

The characteristic aroma of meat usually originates from thermal processes like cooking, roasting or frying. Chemical reactions occurring during heat-treatment involve degradation of amino acids, peptides, sugars, ribonucleotides, lipids and vitamins. The key process in the aroma formation is Maillard reaction that occurs between reducing sugars and amino acids derivatives. The characteristic compounds for cooked meat are aldehydes, ketones, alcohols, hydrocarbons, pyrazine derivatives and sulphur compounds (Cañedo et al., 2011).

A specific effect is the warmed-over flavour (WOF), which develops during storage in meat after cooking. It comes from lipid oxidation induced by iron released from myoglobin and hemoglobin during cooking. The unpleasant odour is described as "metallic", "musty" and "pungent" and the secondary oxidation products responsible for it are hexanal, 2,3-octanediol, pentanal, 2-pentylfurane and 2-octenal (Kim et al., 2016; Tikk et al., 2008)

Another process connected to odour development apart from heat treatment of meat is spoilage. During storage the bacterial activity leads to the production of volatile organic compounds of unpleasant odour, most of which are easily identifiable (methanol, ethanol, dimethyl sulfide, methyl thioacetate, toluene, nonane, 2,3-butanediol and others) (Leroy et al., 2009; Casaburi et al., 2015). Alcohols, hydrocarbons, aliphatic ketones, volatile acids and benzenic compounds are the compounds typical for physicochemical changes generated as a result of fat decomposition and lipid oxidation (del Olmo et al., 2014).

The aroma profile of meat can be influenced by different factors like fat content, animal diet, breed, $\mathrm{pH}$, storage condition or heat treatment method. This subject is still not fully explored despite of many discussions (Calkins \& Hodgen, 2007). Assessment of meat freshness can be done by analysis of mixture of volatile organic compounds. Classical methods of analysis of the meat aroma profile involve gas chromatography (GC) and olfactometry (O). A fusion of these two techniques, GC-O, combines the ability of the chromatographic unit to separate different compounds and the capability of the olfactometric system to characterize them (Biniecka \& Caroli, 2011). Apart from chemical methods, the sensory descriptive analysis is still of great significance.

The aroma profile is difficult to analyse and characterize in the laboratory since the human sense of smell does not distinguish individual components but rather identifies the specific mixture of volatiles as a whole. Classical methods of chemical analysis based on gas chromatography result in identification and quantification of particular compounds which can be considered the most important odour indicators. Often single 
compounds present in meaningful quantity in aroma profile are not noticeable by human sense of smell. The practice shows that there is not always a simple correlation between the concentration of particular compounds and the odour perception (MildnerSzkudlarz et al., 2007).

Electronic noses are analytical instruments designed to mimic the work of human sense of smell. In this technique the analytic process does not concentrate on the identification and quantification of the components of the mixture of volatile compounds but rather on the quantitative description of the complete aroma profile, including the relationships between its components. In many researches the time change of profile or profile change in relation to standard profile is important. In such cases volatile profile is a fingerprint typical for certain test (Liang et al., 2008). The most important issues are presented below. The standard e-nose equipment is based on a series of gas sensors able to collect the chemical signal coming from the headspace and to transmit it to the electronic devices. Different types of sensors can be used for different applications, among them the most popular are electrochemical sensors like metal oxide semiconductors (MOS) or conducting polymers (CP) and piezoelectric sensors like quartz microbalances (QCM). Optical, calorimetric and biosensors can be also incorporated into the e-nose system.

Those innovative types of e-noses based on gas chromatography (GC) or gas chromatography with mass spectrometry (GC/MS) have been introduced recently and their high utility has been demonstrated. In this type of detection each peak from a mass spectrum or a chromatogram acts as a "sensor" providing also information about the chemical structure of the corresponding compound (Nurjuliana et al., 2011). Usually it is a standard to couple e-nose with multivariate software equipped with software tools for chemometric interpretation of sensor signals. The data collected from the sensors are analysed using various statistical tools in order to create a numerical model of the aroma profile of the sample. When having a quantitative description of the aroma profile of samples one can then compare the unknown samples with the reference materials or study the influence of different factors on the odour. The most effective statistical methods used in these types of investigation include principal component analysis (PCA), partial least squares regression (PLSR), linear and canonical discriminant analysis (LDA and CDA) or artificial neural networks (ANN).

Although the e-noses are rather an unreliable tool for the determination of specific chemical compounds constituting the aroma profile, the advantages of this method over the traditional ones are conspicuous. The analyses are fast, simple and low-cost, what makes the e-nose a gratifying analytical method for quality-control applications. However, this technique requires specific and time-consuming training for staff.

This review paper aims to present diversity of types of e-noses used for evaluation of meat and meat products. Prospects for the future development of this technique are presented. Methods and research results discussed in this manuscript may be a guideline for practical e-nose application.

\section{Applications of e-nose in meat analysis}

\subsection{Spoilage monitoring}

Traditional methods of meat spoilage monitoring are based on measurements of chemical or biological spoilage indicators. Standard tests include total bacterial count (TBC) (Casaburi et al., 2015), rancidity measurements with thiobarbituric acid reactive substances assay (TBARS) (Nakyinsige et al., 2015), determination of VOCs by GC-MS and total volatile basic nitrogen (TVBN) measurements (Jaffrès et al., 2011). Colour evaluation and sensory descriptive analysis can be also useful in the detection of spoiled samples (Dissing et al., 2013). However, all these methods are rather costly, time consuming and require specialized staff, what makes them difficult for on-line applications. As the spoilage process is strongly connected with odour changes, the most of studies investigate the possibilities of employing e-nose to this purpose (Table 1).

A standard procedure in this type of study involves choosing the storage conditions (type of packaging and temperature), usually mimicking storage in typical household or industrial conditions and analysing samples after different periods of time. A special attention must be paid to ensure careful preparation of the samples in order to preserve the headspace composition during storage and analysis. The sensor types used for this purpose include mainly metal oxide semiconductors or conducting polymers. During last years a few applications using colorimetric sensors could be noticed (Salinas et al., 2014a; Chen et al., 2014). The statistical tools employed for data analysis involve multivariate statistics and artificial neuron networks. The obtained results are then confronted with data from reference methods based on microbiological evaluation, sensory descriptive analysis or chemical determination of spoilage indicators (Table 1).

A number of fully successful attempts to employ e-noses for meat spoilage monitoring prove the utility of this analytic tool. Therefore e-nose found application as a laboratory tool, yet no in industrial practice. The prospects of method development involve further investigation of the value of information coming from particular sensors and constructing new portable instruments with reduced number of sensors in order to minimize costs and simplify the analysis.

\subsection{Differentiation between types of meat}

Determination of the animal species from which the meat was produced is an important problem of food analysis. From the consumer's point of view it is an essential issue not only because of quality of the product or meat adulteration but also because of health, dietary and religious aspects. The classical methods of meat species identification involve expensive and time consuming molecular biology-based methods or spectroscopic measurements requiring specialized equipment and complex data analysis. It has been recently demonstrated that e-nose can be a reliable analytic tool for screening of meat samples for animal species origin.

A successful differentiation between meat samples from sheep, cattle, poultry, and swine was performed using an electronic nose based on gas chromatography (Nurjuliana et al., 2011). A simple 
Table 1. Applications of e-noses in meat analysis.

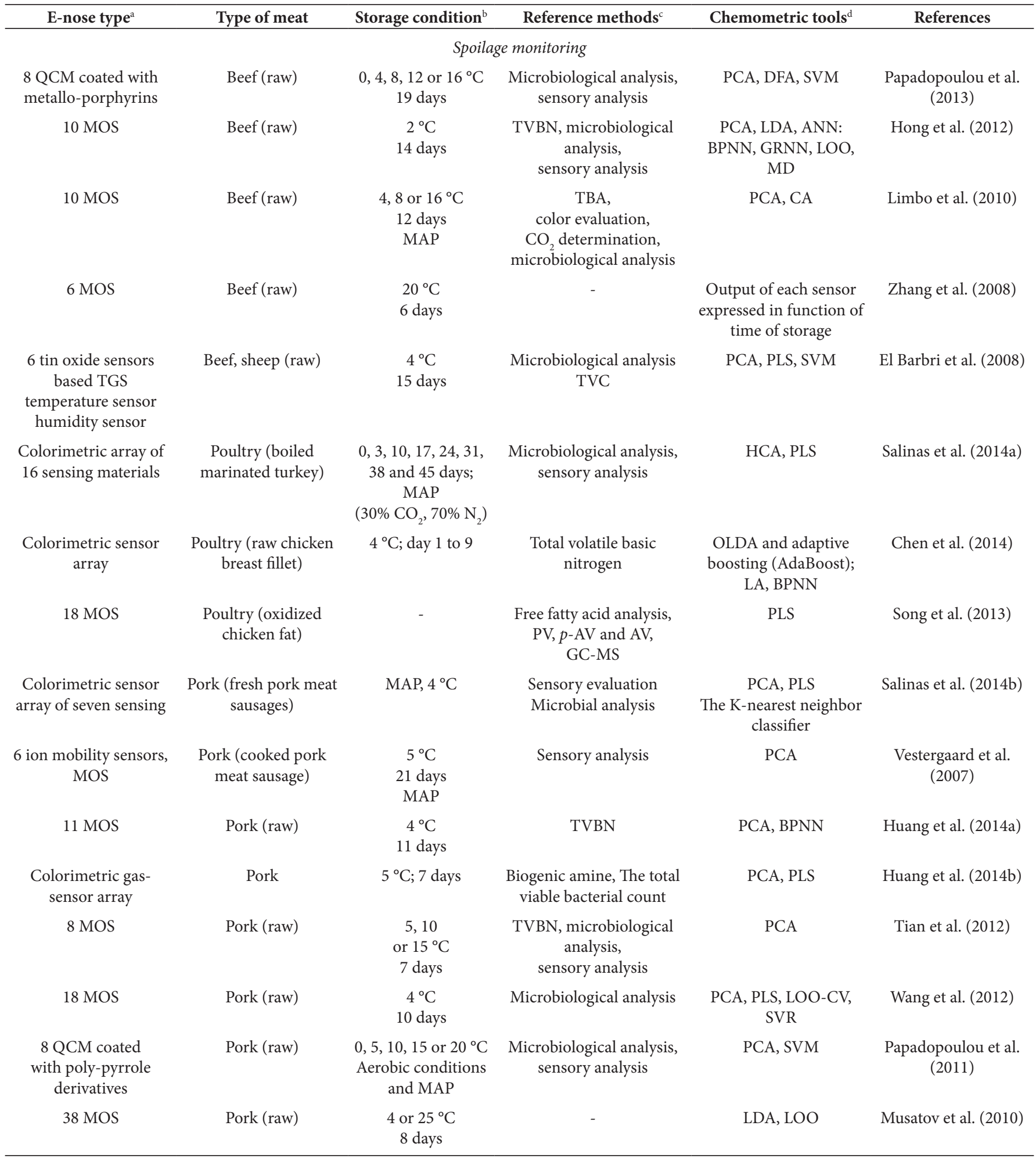

${ }^{a}$ MOS - metal oxide semiconductor sensor; MOSFET - metal oxide semiconductor field effect transistor sensor. CP - conducting polymer sensor; QCM - quartz crystal microbalance; TGS - Taguchi gas sensors; SAW - surface acoustic wave; IMCELL - The ion mobility cell; SCCELL - semiconductor cell. ${ }^{\mathrm{b}}$ If not mentioned otherwise, aerobic conditions. MAP - modified atmosphere-packaged; VP - vacuum-packaged. ' GC - gas chromatography; MS - mass spectrometry; TBA - thiobarbituric acid assay; TVBN - total basic nitrogen determination; PV - peroxide value; $p$-AV - p-anisidine value; AV - acid value; QDA - quantitative descriptive analysis; TVC - the bacteria total viable counts; FRAP - ferric reducing antioxidant power; ABTS - 2,20-azino-bis-(3-ethylbenzthiazoline-6-sulfonic) acid; CAT - catalase; SOD - superoxide dismutase; GPX - glutathione peroxidase; GSH/GSSG - the reduced and oxidised forms glutathione. ${ }^{\mathrm{d}}$ PCA - principal component analysis; PLS - partial least squares regression; FSGDA - forward stepwise general discriminant analysis; RBFN - radial basis function neural network; CDA - canonical discrimination analysis; LDA - linear discrimination analysis; LOO - leave-one-out method; CA - cluster analysis. ANN - artificial neural network; BPNN - back propagation neural network; GRNN - generalized regression neural network; MD - Mahalanobis distance analysis; SVM - support vector machines; CV - cross validation; DFA - discriminant function analysis; ANOVA - analysis of variance; CDA - Canonical discriminant analysis; CCA - canonical-correlation analysis; BDA - Bayes discriminant analysis; MLR - Multiple Linear Regression; PCC - Pearson Correlation coefficients; HCA - hierarchical cluster analysis; OLDA - orthogonal linear discriminant analysis. 
Table 1. Continued...

\begin{tabular}{|c|c|c|c|c|c|}
\hline E-nose type ${ }^{a}$ & Type of meat & Storage condition $^{\mathrm{b}}$ & Reference methods $^{c}$ & Chemometric tools $^{\mathrm{d}}$ & References \\
\hline $\begin{array}{c}\text { FishNose prototype } \\
\text { with } 6 \text { gas sensor array }\end{array}$ & Salmon (cold smoked) & $\begin{array}{c}5^{\circ} \mathrm{C}, 10^{\circ} \mathrm{C} \\
\operatorname{VP}\end{array}$ & $\begin{array}{l}\text { Sensory analysis } \\
\text { (based on QDA) } \\
\text { GC-MS, GC-O }\end{array}$ & PLS, PCA & $\begin{array}{l}\text { Jonsdottir et al. } \\
\qquad(2008)\end{array}$ \\
\hline \multicolumn{6}{|c|}{ Differentiation between types of meat } \\
\hline SAW sensor & $\begin{array}{l}\text { Pork, mutton, chicken, } \\
\text { beef sausages }\end{array}$ & $-20^{\circ} \mathrm{C}$ & GCMS-HS & PCA & $\begin{array}{l}\text { Nurjuliana et al. } \\
\text { (2011) }\end{array}$ \\
\hline $10 \mathrm{MOS}$ & Mutton, pork & $-18^{\circ} \mathrm{C}$ & - & $\begin{array}{c}\text { CDA, BDA, PLS, MLR, } \\
\text { NN }\end{array}$ & Tian et al. (2013) \\
\hline
\end{tabular}

Evaluation the effect of dietary supplementation of animals

\begin{tabular}{|c|c|c|c|c|c|}
\hline $\begin{array}{l}32 \text { conducting } \\
\text { polymer sensors }\end{array}$ & Steer & $-70^{\circ} \mathrm{C}, \mathrm{VP}$ & $\begin{array}{l}\text { FRAP, ABTS_+, CAT, } \\
\text { SOD, GPX, GSH/ GSSG, } \\
\text { a-tocopherol, TBARS }\end{array}$ & PCC, LDA & Descalzo et al. (2007 \\
\hline $\begin{array}{l}\text { GC/FID with the } \\
\text { AroChemBase }\end{array}$ & pork & $\begin{array}{l}-21^{\circ} \mathrm{C}, \\
1 \text { month }\end{array}$ & $\begin{array}{l}\text { vitamin } \mathrm{E} \text {, fatty acids, basic } \\
\text { compositions }\end{array}$ & ANOVA & $\begin{array}{c}\text { Wojtasik- } \\
\text { Kalinowska et al. } \\
\text { (2016) }\end{array}$ \\
\hline
\end{tabular}

Process monitoring in the production

\begin{tabular}{|c|c|c|c|c|c|}
\hline $\begin{array}{c}16 \text { semiconductor } \\
\text { sensors }\end{array}$ & Pork, Iberian ham & $5,10,13$ months & sensory analysis & PCA, ANN & Santos et al. (2004) \\
\hline $12 \mathrm{MOS}$ & pork sausages & $\begin{array}{c}5,7,10,14 \\
\text { seasoning days }\end{array}$ & HS-SPME/GC-MS, HPLC & DFA & Lippolis et al. (2016) \\
\hline \multicolumn{6}{|c|}{ pecific purposes (boar taint and WOF evaluation) } \\
\hline $\begin{array}{c}\text { IMCELL1 with } \\
6 \text { channels IMC, } \\
\text { SCCELL as a seventh } \\
\text { sensor }\end{array}$ & Pork (male pig) & $\begin{array}{l}-80^{\circ} \mathrm{C} \\
+5{ }^{\circ} \mathrm{C}\end{array}$ & $\begin{array}{c}\text { Spectrophotometric } \\
\text { method, ELISA-systems, } \\
\text { sensory analysis }\end{array}$ & PLS, PCA & $\begin{array}{l}\text { Vestergaard et al. } \\
\text { (2006) }\end{array}$ \\
\hline $\begin{array}{l}10 \text { MOSFET } \\
12 \text { MOS }\end{array}$ & $\begin{array}{l}\text { Pork (cooked, raw- } \\
\text { stored and reheated } \\
\text { pork meatballs) }\end{array}$ & $\begin{array}{c}4^{\circ} \mathrm{C} \\
0,2 \text { and } 4 \text { days }\end{array}$ & $\begin{array}{l}\text { GC, HPLC, sensory } \\
\text { analysis }\end{array}$ & PLSR & Tikk et al. (2008) \\
\hline $\begin{array}{c}\text { Colorimetric sensor } \\
\text { array }\end{array}$ & $\begin{array}{c}\text { Poultry } \\
\text { (cooked chicken) }\end{array}$ & $\begin{array}{l}\quad 4^{\circ} \mathrm{C} ; 6 \text { days } \\
\text { reheated in a water } \\
\text { bath at } 100{ }^{\circ} \mathrm{C}\end{array}$ & TBARS, GC & PCA, PLSR, HCA & Kim et al. (2016) \\
\hline
\end{tabular}

\begin{abstract}
${ }^{a}$ MOS - metal oxide semiconductor sensor; MOSFET - metal oxide semiconductor field effect transistor sensor. CP - conducting polymer sensor; QCM - quartz crystal microbalance; TGS - Taguchi gas sensors; SAW - surface acoustic wave; IMCELL - The ion mobility cell; SCCELL - semiconductor cell. ${ }^{\mathrm{b}}$ If not mentioned otherwise, aerobic conditions. MAP - modified atmosphere-packaged; VP - vacuum-packaged. ${ }^{c} \mathrm{GC}$ - gas chromatography; MS - mass spectrometry; TBA - thiobarbituric acid assay; TVBN - total basic nitrogen determination; PV - peroxide value; $p$-AV - p-anisidine value; AV - acid value; QDA - quantitative descriptive analysis; TVC - the bacteria total viable counts; FRAP - ferric reducing antioxidant power; ABTS - 2,20-azino-bis-(3-ethylbenzthiazoline-6-sulfonic) acid; CAT - catalase; SOD - superoxide dismutase; GPX - glutathione peroxidase; GSH/GSSG - the reduced and oxidised forms glutathione. ${ }^{\mathrm{d}}$ PCA - principal component analysis; PLS - partial least squares regression; FSGDA - forward stepwise general discriminant analysis; RBFN - radial basis function neural network; CDA - canonical discrimination analysis; LDA - linear discrimination analysis; LOO - leave-one-out method; CA - cluster analysis. ANN - artificial neural network; BPNN - back propagation neural network; GRNN - generalized regression neural network; MD - Mahalanobis distance analysis; SVM - support vector machines; CV - cross validation; DFA - discriminant function analysis; ANOVA - analysis of variance; CDA - Canonical discriminant analysis; CCA - canonical-correlation analysis; BDA - Bayes discriminant analysis; MLR - Multiple Linear Regression; PCC - Pearson Correlation coefficients; HCA - hierarchical cluster analysis; OLDA - orthogonal linear discriminant analysis.
\end{abstract}

statistical data analysis using principal component analysis (PCA) could clearly separate groups of samples derived from different animals. Moreover, although the e-noses generally do not give information about chemical composition of the headspace, the chromatographic analysis performed by this type of e-nose allowed the tentative identification of compounds responsible for the aroma profile, using Kovat's indices. The methodology presented in the study was extremely simple, fast and no-expensive, providing a useful tool for food analysis.

The ability of electronic nose to discriminate between types of meat can be also applied in the detection of meat adulteration with proteins from another, cheaper species. Pork adulteration in minced mutton was studied with an e-nose containing 10 metal oxide sensors (Tian et al., 2013). Mutton samples, as described by Tian et al. (2013), were mixed with pork in different proportions and the headspace of each sample was tested with the e-nose. Various statistic tools were implemented to analyse the data obtained (PCA, DA, PLS, MLR and BPNN) and it was clearly demonstrated that the e-nose methodology coupled with multivariate analysis can easily predict the degree of adulteration of pork in minced mutton.

There are also other possibilities to use e-nose technique for meat type and quality differentiation for meat adulteration detection and for quality control (Sentandreu \& Sentandreu, 2014). 


\subsection{Evaluation of the effect of dietary supplementation of animals}

Animal nutrition has a potent influence on meat quality. Different types of dietary regimes can be applied for specific purposes, among them supplementation of functional ingredients such as vitamin E, selenium, conjugated linoleic acids or omega-3 fatty acids gained a special interest over last years (Zhang et al., 2010). Evaluation of the relationship between animal diet and meat attributes is an important feature.

Descalzo et al. (2007) performed an investigation of animal diet influence on overall antioxidant power in meat and its connection with the aroma profile. Crossbreed steers were either pasture or grain-fed and in both groups a part of animals obtained an additional vitamin E supplementation. An e-nose with 32 conducting polymer sensors was used to analyse the aroma profile of fresh beef samples from all the four groups. Antioxidant capacity tests were also performed. The relationship between the e-nose data and the antioxidant status related variables was analysed while the linear discriminant analysis of e-nose measurements was employed to investigate the meat samples grouping as a function of feeding. The e-nose distinguished correctly grain and pasture produced meat as well as supplemented and non-supplemented with vitamin $\mathrm{E}$ grain produced meat. These results show that the aroma profile of meat is strongly related on the antioxidant status which affects the lipids oxidation influencing the consequent production of volatile short chained aldehydes. The e-nose proved therefore to be a useful tool to discriminate the aroma profile of fresh meat samples with different antioxidant potential.

The influence of animal dietary regimes on lipid oxidation can manifest in the change of volatile compounds profile of meat and this effect was also investigated with the use of e-nose (Wojtasik-Kalinowska et al., 2016). In described experiment, pigs were divided into four feeding groups with different diets: control diet, supplemental vitamin $\mathrm{E}$ and organic selenium diet, supplemental organic selenium diet and supplemental vitamin E diet. The samples were analysed using electronic nose equipped with ultrafast gas chromatograph with flame-ionization detectors. The e-nose data were analysed using the AroChemBase database and ANOVA. The measurements performed by e-nose showed that the addition of antioxidants to pigs feed prevented the formation of sulphur compounds in raw meat. The electronic nose successfully allowed to determine seventeen specific volatile compounds in supplemented meat.

\subsection{Production process monitoring}

There are rather few examples in literature of direct use of e-nose for production process monitoring. Usually these are older references such as e-nose usage to identify spoiled Iberian hams during the curing process (Santos et al., 2004). They discussed use of e-nose for recognition of different Iberian ham ripening times. The sensors with tin-oxide semiconductor thin films were used for the tests. Some of the sensors were doped with metal catalysts. PCA was used for results analysis together with artificial neural network.
Electronic nose can be applied to study dynamic processes occurring during production of sausages. An investigation of the seasoning processes for dry-cured meats was performed with an electronic nose containing 12 metal oxide sensors (Lippolis et al., 2016). Fresh pork sausages were subjected to the manufacture's protocols and 5, 7, 10, 14 days seasoning. Research included monitoring of presence of ochratoxin A-producing and non-producing Penicillium strains during the seasoning process. Food contamination with ochratoxins is very dangerous for humans and is considered as possibly carcinogenic by The International Agency for Research on Cancer in 1993. The e-nose data were analysed using DFA. Proposed research technique was successfully applied for rapid prediction of ochratoxin A.

These mentioned applications of e-nose are satisfactory examples of successful use of e-nose based systems for quality control.

\subsection{Specific purposes: boar taint and WOF evaluation}

'Boar taint' and WOF are the sensory defects in meat flavour. 'Boar taint' is characteristic for pork derived from non-castrated male pigs. It is connected to the presence of androstenone and skatole but it was shown that the sensory evaluation of the "boar taint' level does not always agree with the absolute concentrations of these two compounds (Vestergaard et al., 2006). There is therefore a demand for developing a system able to efficiently discriminate between different intensities of this undesirable odour. Vestergaard et al. (2006) used e-nose and sensory panel to measure the intensity of "boar taint" in entire male pigs. An electronic nose based on ion mobility spectrometry was employed to mimic the responses given by the sensory panel. The data from e-nose analysis were calibrated using canonical correlation with the sensory measurement and a discriminant function for separating levels of boar taint in pork by e-nose was developed. Sensoric research affirmed stronger correlation of boar taint with androstenone than with skatole. The research showed that e-nose technique based on ion mobility spectrometry may have a potential for a rapid sorting of boar fat at the slaughter line.

The warmed-over flavour develops in meat which has been pre-cooked, chill stored and reheated. Tikk et al. (2008) carried out sensory analysis of volatile compounds on meatballs derived from pigs fed with standard diet supplemented with addition of rapeseed and palm oil using solid state based gas sensor array system (e-nose) and gas chromatography/gas spectrometry together with measurements of thiobarbituric acid reactive substances (TBARS). Obtained data were analysed using partial least square regression modelling (PLSR). MOS sensor responses showed to be significantly related to WOF characteristics detected by both sensory and chemical analysis. This shows the potential of using gas sensor technology to monitor WOF in pork.

The simple and rapid method of prediction of WOF in cooked chicken by colorimetric sensor array was a subject of research of Su Yeon Kim et al. (2016). Data from colorimetric sensor array was classified using principle component analysis and hierarchical cluster analysis. Research showed that colorimetric sensor array may be successfully used to predict WOF development in cooked chicken meat. 


\section{Conclusions}

In the recent years it was demonstrated that electronic noses provide a fast, simple and non-destructive method of meat analysis. E-noses were successfully employed mainly in the quality control of meat being able to monitor spoilage or adulterations and the obtained results were in accordance with the sensory evaluation, offering a reliable tool for on-line analysis. The ability of e-nose to determine the antioxidant status of meat samples was also proved. It can be stated that every factor that influences the aroma profile of meat, could be potentially indirectly analysed with the e-nose system and this field still seems to be insufficiently explored. Moreover, the development of new types of e-noses, based on gas chromatography, opens new perspectives for analysis of the aroma profile of meat.

Despite of many scientific works proving usefulness of e-nose based on different types of sensors or GC techniques for meat quality appraisal or spoilage detection, use of e-nose in industry practice is insufficient. There was not found any description or report on large scale industrial application of e-nose. Almost every paper describes potentially large possibilities of use of e-nose in industrial practice, but none reports real-life implementation. This may be explained by sensor vulnerability (sensor time drift), relatively high e-nose costs and effort consuming staff training. The above does not mean that e-nose will not be used widely in future in industrial practice. There is still lack of effective application, although the potential of e-nose approach was proven.

\section{Acknowledgements}

This work was realized within the project "BIOFOOD - innovative functional products of animal origin" no. POIG.01.01.02-014090/09, co-financed by the European Union from the European Regional Development Fund within the Innovative Economy Operational Programme 2007-2013.

\section{References}

Acevedo, C. A., Creixell, W., Pavez-Barra, C., Sánchez, E., Albornoz, F., \& Young, M. E. (2012). Modeling volatile organic compounds released by bovine fresh meat using an integration of solid phase microextraction and databases. Food and Bioprocess Technology, 8(6), 2557-2567. http://dx.doi.org/10.1007/s11947-011-0571-1.

Biniecka, M., \& Caroli, S. (2011). Analytical methods for the quantification of volatile aromatic compounds. Trends in Analytical Chemistry, 30(11), 1756-1770. http://dx.doi.org/10.1016/j.trac.2011.06.015.

Calkins, C. R., \& Hodgen, J. M. (2007). A fresh look at meat flavour. Meat Science, 77(1), 63-80. http://dx.doi.org/10.1016/j.meatsci.2007.04.016. PMid:22061397.

Cañedo, A. R., Juez-Ojeda, C., Nuñez, M., \& Fernández-García, E. (2011). Effects of high-pressure processing on the volatile compounds of sliced cooked pork shoulder during refrigerated storage. Food Chemistry, 124(3), 749-758. http://dx.doi.org/10.1016/j.foodchem.2010.06.091.

Casaburi, A., Piombino, P., Nychas, G. J., Villani, F., \& Ercolini, D. (2015). Bacterial populations and the volatilome associated to meat spoilage. Food Microbiology, 45(Pt A), 83-102. http://dx.doi. org/10.1016/j.fm.2014.02.002. PMid:25481065.

Chen, Q., Hui, Z., Zhao, J., \& Ouyang, Q. (2014). Evaluation of chicken freshness using a low-cost colorimetric sensor array with AdaBooste-
OLDA classification algorithm. LWT - Food Science and Technology (Campinas.), 57, 502-507.

del Olmo, A., Calzada, J., \& Nuñez, M. (2014). Effect of high-pressureprocessing and modified-atmosphere-packing on the volatile compounds and odour characteristics of sliced ready-to-eat "lacon", a cured-cooked pork meat product. Innovative Food Science \& Emerging Technologies, 26, 134-142. http://dx.doi.org/10.1016/j. ifset.2014.09.009.

Descalzo, A. M., Rossetti, L., Grigioni, G., Irurueta, M., Sancho, A. M., Carrete, J., \& Pensel, N. A. (2007). Antioxidant status and odour profile in fresh beef from pasture or grain-fed cattle. Meat Science, 75(2), 299-307. http://dx.doi.org/10.1016/j.meatsci.2006.07.015. PMid:22063662.

Dissing, B. S., Papadopoulou, O. S., Tassou, C., Ersbøll, B. K., Carstensen, J. M., Panagou, E. Z., \& Nychas, G. J. (2013). Using multispectral imaging for spoilage detection of pork meat. Food and Bioprocess Technology, 6(9), 2268-2279. http://dx.doi.org/10.1007/s11947012-0886-6.

El Barbri, N., Llobet, E., El Bari, N., Correig, X., \& Bouchikhi, B. (2008). Electronic nose based on metal oxide semiconductor sensors as an alternative technique for the spoilage classification of red meat. Sensors (Basel, Switzerland), 8(1), 142-156. http://dx.doi. org/10.3390/s8010142.

Hong, X., Wang, J., \& Hai, Z. (2012). Discrimination and prediction of multiple beef freshness indexes based on electronic nose. Sensors and Actuators B, Chemical, 161(1), 381-389. http://dx.doi.org/10.1016/j. snb.2011.10.048.

Huang, L., Zhao, J., Chen, Q., \& Zhang, Y. (2014a). Nondestructive measurement of total volatile basic nitrogen (TVB-N) in pork meat by integrating near infrared spectroscopy, computer vision and electronic nose techniques. Food Chemistry, 145, 228-236. http:// dx.doi.org/10.1016/j.foodchem.2013.06.073. PMid:24128472.

Huang, X. W., Zou, X. B., Shi, J. Y., Guo, Y., Zhao, J. W., Zhang, J., \& Hao, L. (2014b). Determination of pork spoilage by colorimetric gas sensor array based on natural pigments. Food Chemistry, 145, 549-554. http://dx.doi.org/10.1016/j.foodchem.2013.08.101. PMid:24128513.

Jaffrès, E., Lalanne, V., Macé, S., Cornet, J., Cardinal, M., Sérot, T., Dousset, X., \& Joffraud, J. J. (2011). Sensory characteristics of spoilage and volatile compounds associated with bacteria isolated from cooked and peeled tropical shrimps using SPME-GC-MS analysis. International Journal of Food Microbiology, 147(3), 195-202. http:// dx.doi.org/10.1016/j.ijfoodmicro.2011.04.008. PMid:21531471.

Jonsdottir, R., Olafsdottir, G., Chanie, E., \& Haugen, J. E. (2008). Volatile compounds suitable for rapid detection as quality indicators of cold smoked salmon (Salmo salar). Food Chemistry, 109(1), 184-195. http://dx.doi.org/10.1016/j.foodchem.2007.12.006. PMid:26054280.

Khan, M. I., Jo, C., \& Tariq, M. R. (2015). Meat flavor precursors and factors influencing flavor precursors: a systematic review. Meat Science, 110, 278-284. http://dx.doi.org/10.1016/j.meatsci.2015.08.002. PMid:26319308.

Kim, S.-Y., Li, J., Lim, N.-R., Kang, B.-S., \& Park, H.-J. (2016). Prediction of warmed-over flavour development in cooked chicken by colorimetric sensor array. Food Chemistry, 211, 440-447. http:// dx.doi.org/10.1016/j.foodchem.2016.05.084. PMid:27283653.

Leroy, F., Vasilopoulos, C., Van Hemelryck, S. V., Falony, G., \& De Vuyst, L. (2009). Volatile analysis of spoiled, artisan-type, modifiedatmosphere-packed cooked ham stored under different temperatures. Food Microbiology, 26(1), 94-102. http://dx.doi.org/10.1016/j. fm.2008.08.005. PMid:19028312. 
Liang, Q., Wang, J. R., \& Liang, Z. S. (2008). Establishment of GC fingerprint of essential oil of Salvia Miltiorrhiza flower. Journal of Northwest Forestry University, 23(4), 152-155.

Limbo, S., Torri, L., Sinelli, N., Franzetti, L., \& Casiraghi, E. (2010). Evaluation and predictive modelling of shelf life of minced beef stored in high-oxygen modified atmosphere packaging at different temperatures. Meat Science, 84(1), 129-136. http://dx.doi.org/10.1016/j. meatsci.2009.08.035. PMid:20374764.

Lippolis, V., Ferrara, M., Cervellieri, S., Damascelli, A., Epifani, F., Pascale, M., \& Perrone, G. (2016). Rapid prediction of ochratoxin A-producing strains of Penicillium on dry-cured meat by MOSbased electronic nose. International Journal of Food Microbiology, 218, 71-77. http://dx.doi.org/10.1016/j.ijfoodmicro.2015.11.011. PMid:26619315.

Mildner-Szkudlarz, S., Zawirska-Wojtasik, R., Korczak, J., \& Jeleń, H. H. (2007). A comparison of human and electronic nose responses to flavor of various food products of different degree of lipids oxidation. Polish Journal of Food and Nutrition Sciences, 57(2), 195-202.

Musatov, V. Y., Sysoev, V. V., Sommer, M., \& Kiselev, I. (2010). Assessment of meat freshness with metal oxide sensor microarray electronic nose: A practical approach. Sensors and Actuators. B, Chemical, 144(1), 99-103. http://dx.doi.org/10.1016/j.snb.2009.10.040.

Nakyinsige, K., Sazili, A. Q., Aghwan, Z. A., Zulkifli, I., Goh, Y. M., Abu Bakar, F., \& Sarah, S. A. (2015). Development of microbial spoilage and lipid and protein oxidation in rabbit meat. Meat Science, 108, 125131. http://dx.doi.org/10.1016/j.meatsci.2015.05.029. PMid:26115345.

Nurjuliana, M., Che Man, Y. B., Mat Hashim, D., \& Mohamed, A. K. S. (2011). Rapid identification of pork for halal authentication using the electronic nose and gas chromatography mass spectrometer with headspace analyser. Meat Science, 88(4), 638-644. http://dx.doi. org/10.1016/j.meatsci.2011.02.022. PMid:21420795.

O'Sullivan, M. G., \& Kerry, J. P. (2009). Sensory evaluation of fresh meat. In J.P. Kerry \& D.A. Ledward (Eds.), Improving the sensory and nutritional quality of fresh meat (chap. 8; pp. 178-196). Cambridge: Woodhead Publishing Limited.

Papadopoulou, O. S., Panagou, E. Z., Mohareb, F. R., \& Nychas, G. J. E. (2013). Sensory and microbiological quality assessment of beef fillets using a portable electronic nose in tandem with support vector machine analysis. Food Research International, 50(1), 241-249. http:// dx.doi.org/10.1016/j.foodres.2012.10.020.

Papadopoulou, O. S., Tassou, C. C., Schiavo, L., Nychas, G. J. E., \& Panagou, E. Z. (2011). Rapid assessment of meat quality by means of an electronic nose and support vector machines. Procedia Food Science, 1, 2003-2006. http://dx.doi.org/10.1016/j.profoo.2011.09.295.

Salinas, Y., Ros-Lis, J. V., Vivancos, J. L., Martínez-Mánez, R., Aucejo, S., Herranz, N., Lorente, I., \& Garcia, E. (2014a). A chromogenic sensor array for boiled marinated turkey freshness monitoring. Sensors and Actuators. B, Chemical, 190, 326-333. http://dx.doi. org/10.1016/j.snb.2013.08.075.

Salinas, Y., Ros-Lis, J. V., Vivancos, J. L., Martínez-Máñez, R., Marcos, M. D., Aucejo, S., Herranz, N., Lorente, I., \& Garcia, E. (2014b). A novel colorimetric sensor array for monitoring fresh pork sausages spoilage. Food Control, 35(1), 166-176. http://dx.doi.org/10.1016/j. foodcont.2013.06.043.

Santos, J. P., Garcia, M., Aleixandre, M., Horrillo, M. C., Gutierrez, J., Sayago, I., Fernandez, M. J., \& Ares, L. (2004). Electronic nose for identification of pig feeding and ripening time in Iberian hams. Meat Science, 66(3), 727-732. http://dx.doi.org/10.1016/j. meatsci.2003.07.005. PMid:22060883.

Sentandreu, M. A., \& Sentandreu, E. (2014). Authenticity of meat products: tools against fraud. Food Research International, 60, 19-29.

Song, S., Yuan, L., Zhang, X., Hayat, K., Chen, H., Liu, F., Xiao, Z., \& Niu, Y. (2013). Rapid measuring and modelling flavour quality changes of oxidised chicken fat by electronic nose profiles through the partial least squares regression analysis. Food Chemistry, 141(4), 4278-4288. http://dx.doi.org/10.1016/j.foodchem.2013.07.009. PMid:23993616.

Tian, X., Wang, J., \& Cui, S. (2013). Analysis of pork adulteration in minced mutton using electronic nose of metal oxide sensors. Journal of Food Engineering, 119(4), 744-749. http://dx.doi.org/10.1016/j. jfoodeng.2013.07.004.

Tian, X.-Y., Cai, Q., \& Zhang, Y.-M. (2012). Rapid classification of hairtail fish and pork freshness using an electronic nose based on the PCA method. Sensors (Basel, Switzerland), 12(1), 260-277. PMid:22368468.

Tikk, K., Haugen, J. E., Andersen, H. J., \& Aaslyng, M. D. (2008). Monitoring of warmed-over flavour pork using the electronic nose: correlation to sensory attributes and secondary lipid oxidation products. Meat Science, 80(4), 1254-1263. http://dx.doi.org/10.1016/j. meatsci.2008.05.040. PMid:22063866.

Vestergaard, J. S., Haugen, J. E., \& Byrne, D. V. (2006). Application of an electronic nose for measurements of boar taint in entire male pigs. Meat Science, 74(3), 564-577. http://dx.doi.org/10.1016/j. meatsci.2006.05.005. PMid:22063061.

Vestergaard, J. S., Martens, M., \& Turkki, P. (2007). Application of an electronic nose system for prediction of sensory quality changes of a meat product (pizza topping) during storage. $L W T$ - Food Science and Technology (Campinas.), 40, 1095-1101.

Wang, D., Wang, X., Liu, T., \& Liu, Y. (2012). Prediction of total viable counts on chilled pork using an electronic nose combined with support vector machine. Meat Science, 90(2), 373-377. http://dx.doi. org/10.1016/j.meatsci.2011.07.025. PMid:21871741.

Wojtasik-Kalinowska, I., Guzek, D., Górska-Horczyczak, E., Głąbska, D., Brodowska, M., Sun, D.-W., \& Wierzbicka, A. (2016). Volatile compounds and fatty acids profile in Longissimus dorsi muscle from pigs fed with feed containing bioactive components. LWT - Food Science and Technology (Campinas.), 67, 112-117.

Zhang, W., Xiao, S., Samaraweera, H., Lee, E. J., \& Ahn, D. U. (2010). Improving functional value of meat products. Meat Science, 86(1), 1531. http://dx.doi.org/10.1016/j.meatsci.2010.04.018. PMid:20537806.

Zhang, Z., Tong, J., Chen, D., \& Lan, Y. (2008). Electronic nose with an air sensor matrix for detecting beef freshness. Journal of Bionics Engineering, 5(1), 67-73. http://dx.doi.org/10.1016/S16726529(08)60008-6. 